\title{
Reduction in and Preventive Effects for Oral-Cancer Risk with Antidepressant Treatment
}

\author{
Chia-Min Chung ${ }^{1,2,3}$, Tzer-Min Kuo ${ }^{3}$, Kun-Tu Yeh $^{4}\left(\mathbb{D}\right.$, Chien-Hung Lee ${ }^{5}$ and Ying-Chin Ko ${ }^{3, * \mathbb{C}}$ \\ 1 Center for Drug Abuse and Addiction, China Medical University Hospital, Taichung 40447, Taiwan; \\ Ibmsn141@gmail.com \\ 2 Graduate Institute of Biomedical Sciences, China Medical University, Taichung 40447, Taiwan \\ 3 Environment-Omics-Diseases Research Centre, China Medical University Hospital, China Medical University, \\ No. 2 Yude Road, Taichung 40447, Taiwan; tzermin@hotmail.com \\ 4 Department of Pathology, Changhua Christian Hospital, Changhua 50006, Taiwan; 10159@cch.org.tw \\ 5 Department of Public Health, College of Health Science, Kaohsiung Medical University, Kaohsiung 80708, \\ Taiwan; cnhung@kmu.edu.tw \\ * Correspondence: ycko0406@gmail.com or T27032@mail.cmuh.org.tw; Tel.: +886-4-2205-2121 (ext. 2028)
}

Citation: Chung, C.-M.; Kuo, T.-M.; Yeh, K.-T.; Lee, C.-H.; Ko, Y.-C. Reduction in and Preventive Effects for Oral-Cancer Risk with Antidepressant Treatment. J. Pers. Med. 2021, 11, 591. https://doi.org/ 10.3390/jpm11070591

Academic Editor: Shyng-Shiou F Yuan

Received: 4 May 2021

Accepted: 20 June 2021

Published: 23 June 2021

Publisher's Note: MDPI stays neutral with regard to jurisdictional claims in published maps and institutional affiliations.

Copyright: (c) 2021 by the authors. Licensee MDPI, Basel, Switzerland. This article is an open access article distributed under the terms and conditions of the Creative Commons Attribution (CC BY) license (https:// creativecommons.org/licenses/by/ $4.0 /)$.

\begin{abstract}
Areca nut (AN) was identified as carcinogenic to humans. Around 600 million people globally use AN in some form, yet no effective therapeutic drug is available to overcome AN addiction. This preclinical study examines the effects of antidepressants on AN use with animal models. We produced AN powder and dissolved it into drinking water, training 55 C57BL/6 mice in free self-selection to drink AN water or normal water. Then, the mice were randomly divided into four groups. Selective serotonin reuptake inhibitors (SSRIs), monoamine oxidase inhibitors (MAOIs), and tricyclic antidepressants (TCAs) were given as three treatment groups and one placebo group for four weeks. In the follow-up period, the preference and amount of free selection of AN and normal water, and oral pathological change were evaluated. There was a significant decrease in preference for AN drinking during the first four weeks, and the 36th week after drug withdrawal in the MAOI and SSRI groups (all $p<0.05$ ). The drug-reducing effect of AN water in the 1-4-week period was significant in the MAOI group $(p<0.0001)$ and was also significant in the 3 -4-week period in the SSRI group $(p=0.03)$. The TCA group did not show a decrease effect. At the endpoint (60 weeks), oral mucosal fibrosis (OSF) levels and risk in the SSRI $(p=0.0081)$ and MAOI $(p=0.01)$ groups were significantly lower than those in the control group. Antidepressant drugs MAOIs and SSRIs could reduce the amount of AN use and decrease the early stage of oral fibrosis in mice, but SSRIs may need to be boosted again.
\end{abstract}

Keywords: areca nut; antidepressants; oral submucous fibrosis; mouse model; betel quid; oral cancer

\section{Introduction}

Betel-quid (BQ) chewing is common in South and Southeast Asia. It is estimated that, currently, $10 \%$ of the global population or nearly 600 million individuals regularly chew BQ [1,2]. Although BQ preparation methods vary among cultures and individuals, the areca nut $(\mathrm{AN})$ is common component in all types of $\mathrm{BQ}$ preparation. The International Agency for Research on Cancer (IARC) has recognized the addictive properties of AN since 1985 and classified AN as carcinogenic to humans (Group 1) in 2004 [3]. AN consumption is associated with several diseases, such as oral potentially malignant disorders (OPMD) [4-7], oral-cavity and upper aerodigestive malignancies [8-12], metabolic syndromes [13], cardiovascular diseases [14], and adverse birth effects [15].

Winstock et al. reported that AN is the fourth most addictive substance [16]. Studies of its chemical constituents demonstrated that AN contains $0.15-0.67 \%$ alkaloids [17]. Psychoactive alkaloids, including the most abundant, arecoline and arecaidine, produce a high level of acetylcholine and monoamines (such as adrenaline and noradrenaline), 
and act as an agonist at muscarinic acetylcholine receptors $[18,19]$. This inhibits the reuptake of gamma-amino butyric acid (GABA) to induce anxiolytic effects. Previously reported research showed that regular $B Q$ chewers have tolerance and a withdrawal syndrome $[16,20]$. Lee et al. conducted a large-scale survey across six Asian populations and found that $B Q$ dependence prevalence among chewers largely varied across populations because of favorable $\mathrm{BQ}$ ingredients and culture-derived features. The one-year prevalence of dependence was 2.8-39.2\% among the six Asian populations, and $20.9-99.6 \%$ of BQ chewers were BQ-dependent [6]. They also found that people who chewed BQ had high prevalence rates of OPMD, especially if they were dependent users [21-23].

Epidemiological data from several populations confirmed that $\mathrm{AN}$ is the major cause of oral submucous fibrosis (OSF) [24], and the proportions of OSF attributable to BQ use were $85 \%$ [25]. The study showed that 99 cases of OSF followed, and it found a $3.72 \%$ malignant-transformation rate for oral cancer (OC) with an average duration of 37.42 months [26]. BQ chewing was reported to be an independent risk factor, with an attributable risk accounting for $79 \%$ of patients with OC in Taiwan [25].

The cessation of AN consumption could be extremely difficult because of the tendency towards relapse and dependence. Quitting rates among AN users are relatively low. The quitting rate among the general population is $18 \%$, and that for the indigenous population in Taiwan is $8 \%$ [27]. Several studies suggested that BQ chewers using tobacco or lime are less likely to quit BQ consumption $[27,28]$.

Therefore, external assistance or even cessation therapy is necessary, yet no effective therapeutic drug is available to overcome BQ dependence.

Our previous study suggested that antidepressant use is associated with reduced risk of OC [29]. The potential mechanism is that antidepressant use may help to reduce or terminate $\mathrm{BQ}$ use, and consequently OSF risk. The limited understanding of the pharmacological basis of intoxication and AN use disorder means that there are no pharmacological replacement therapies for AN use disorder [30,31]. Therefore, in this study, we used animal models to examine the effect of antidepressants on decreasing $B Q$ consumption and reducing $\mathrm{OC}$ risk.

\section{Materials and Methods}

\subsection{Reagents and Areca-Nut Extract (ANE) Preparation}

Fresh ANs were purchased from local commercial stores in Tainan, Taiwan. ANs were weighed, crushed, and incubated at $37^{\circ} \mathrm{C}$ for $2 \mathrm{~h}$. Fibers were removed with two layers of gauze and $90 \mathrm{~m}$ filters. The aqueous ANE was collected and condensed to powder form, and then stored at $-20^{\circ} \mathrm{C}$. Dosing solutions were prepared by dissolving the appropriate amount of ANE powder into distilled water. According to a previous study, lime-containing $\mathrm{BQ}$ users have a significantly higher dependence domain of unsuccessful cut-down [21]. We dissolved $1 \mathrm{~g}$ of lime in $1000 \mathrm{~mL}$ of distilled water $(1 \mathrm{mg} / \mathrm{mL})$. The AN dosages were based on the health effects of years of chewing and daily consumption reported in previous studies [5,25]. Groups of daily consumption over $20 \mathrm{AN}$ and 20 years of the chewing habit had significant risk for OSF or oral leukoplakia. Assuming an average human body weight of $60 \mathrm{~kg}$ and an average daily consumption of $20 \mathrm{AN}$, the dose was $0.25 \mathrm{~g} / \mathrm{mL}$. Considering that the mean body weight of mice during the study period remained at around $30 \mathrm{~g}$ the average dose of AN was approximately $2 \mathrm{mg}$ per day. The average daily consumption of water for mice is approximately $4 \mathrm{~mL}$. The concentration of the AN solution was $500 \mathrm{ug} / \mathrm{mL}$ with $1 \mathrm{mg} / \mathrm{mL}$ lime. 


\subsection{Drug Preparation}

Treatment with antidepressants was administrated via AN water, which mimicked the condition of human AN consumption, and could reduce the effects of the withdrawal symptoms of $\mathrm{BQ}$ chewing. Antidepressant drugs were given at the following doses: imipramine $(10 \mathrm{mg} / \mathrm{kg} /$ day); tricyclic antidepressants (TCA), citalopram (15 mg/kg/day); selective serotonin reuptake inhibitor (SSRI) and moclobemide ( $25 \mathrm{mg} / \mathrm{kg} /$ day); monoamine oxidase inhibitors (MAOI). All drugs were purchased from Sigma-Aldrich (St Louis, MO, USA) and totally administrated in 4 consecutive weeks. The doses of the antidepressant solution were calculated as $\mathrm{mg} / \mathrm{kg}$ for a mouse dose. Imipramine, citalopram, and moclobemide were separately dissolved in distilled water and AN water, then diluted to the desired concentration in one bottle. The doses of antidepressant agents and the time interval between AN cessation administration were modified from the results of various research groups [32-34].

\subsection{Experimental Procedure}

Six-week-old C57BL/ 6 male mice $(n=55)$ were used, purchased from the National Laboratory Animal Center (NLAC, Taiwan), with a rearing-environment temperature of $20-25{ }^{\circ} \mathrm{C}$ and relative humidity of $60-67 \%$. After adaptive feed for 4 weeks, the mice were randomly divided into 4 groups: the MAOI, SSRI, and TCA treatment groups, and the placebo group (AN water). There were ten mice in the SSRI group, 15 mice in the MAOI group, 5 mice in the TCA group, and 25 mice in the placebo group. Placebo groups without applying antidepressants treatment as control groups were observed to assess effects of the consumption amount of areca-nut water and OSF levels in parallel with the use of MAOI and SSRI groups. Free-selection drinking was first used to feed AN water and normal drinking water for 4 weeks. Second, the preference ratio of AN water to normal drinking water was evaluated. Two bottles of water that contained normal drinking water and AN water, respectively, in the same cage were freely selected by mice. The consumption amount was measured for 4 consecutive weeks as the baseline data. A ratio of the amount of AN water consumed to that of normal drinking water greater than 1 was defined as a higher AN preference. Third, treatment with antidepressants was administered via AN water. Fourth, preference-level changes after antidepressant treatment were compared. After the 36-week follow-up, we evaluated the relapse change of AN consumption amount after treatment. According to the literature, the prevalence and risk of OSF increased with chewing duration and daily consumption [5]. Mice were consecutively fed AN water until 60 weeks. After the 60-week follow-up, mice were sacrificed, and pathological changes in oral fibrosis rate and levels were observed. More details are shown in Figure 1. In this study, animal procedures conformed to the guidelines published by the National Institute of Health (NIH publication no. 85-23) and were approved by the Institutional Animal Care and Use Committee (IACUC) of the China Medical University. 
1.Normal water and areca nut water are free selected by mouse

Six-week-old To feed areca nut water

2 . To evaluate preference ratio of areca nut water/ normal water

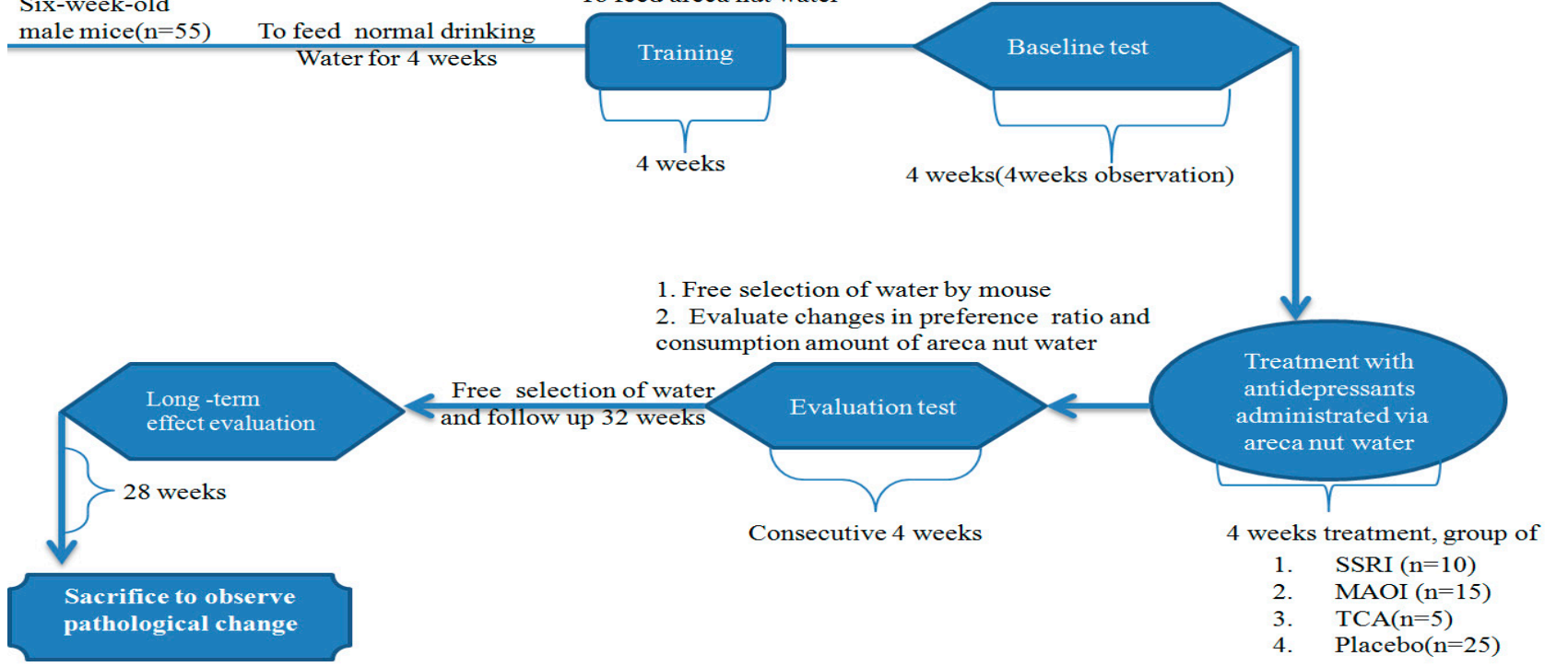

To evaluate oral submucous fibrosis occurrence rate

and levels between treatment and placebo groups

Figure 1. Schematic of evaluation of areca-nut use with antidepressant treatment in animal model.

\subsection{Immunohistochemistry Analysis}

Tongues from the treated mice were fixed in $4 \%$ paraformaldehyde for 3 days and then embedded in paraffin. Then, 3 or $1.5 \mu \mathrm{m}$ sections were stained with hematoxylin and eosin (H\&E) for histological analysis. For the assessment of fibrosis potential, tongue sections were stained with Masson's trichrome by using a Trichrome Modified Masson's Stain Kit (Scytek Labs, Logan, UT, USA). Tongue fibrosis sections from all mice in each group were counted and scored under $100 \times$ magnification. The quantitative measurement (fibrosis index \%) was performed using ImageJ software (version 1.50b) software. OSF cases and severity of precancerous changes were determined by the above averaged fibrosis index $(\geq 5)$. The histopathological classification of OSF patients is suggested in several studies on the basis of fibroblastic response, hyalinized collagen, blood vessel morphology, and lymphocyte infiltration $[35,36]$. In this study, the results of all the immunohistochemical tests were interpreted by two pathologists.

\subsection{Statistical Analysis}

Statistical analysis was performed with SAS 9.2 software (SAS Institute, Cary, NC, USA). Data are presented as mean \pm standard deviation. Multiple sets of average comparison were examined using one-way ANOVA. Changes within and between groups were analyzed using paired-sample $t$ tests and independent-sample $t$ tests, respectively. Categorical and binary variables were compared using the $\chi^{2}$ test or Fisher exact test. Mean changes in AN consumption regarding the amount and preference ratio were compared before and after the antidepressant treatment within groups, then analyzed between groups by MANOVA. Interaction $p$ values are presented for antidepressant treatment * time (before, and after 2, 4, and 36 weeks) effect. Generalized estimating equation (GEE) analyses were performed to examine mean changes from the baseline in repeated-measure assessments with treatment, follow-up, and treatment-follow-up interaction. We analyzed the associations of OSF risk with different antidepressant-treatment groups using the Kaplan-Meier method and the Cox proportional-hazards regression model. 


\section{Results}

\subsection{Safety of Antidepressants in Animal Study}

We conducted an animal study to examine the antidepressant effects on the reduction in AN consumption. We chose those three antidepressant drugs because of their known pharmacokinetics and safety profiles. The effect of long-term AN treatment on mouse body weight was measured every week. We further compared body-weight changes among the MAOI, SSRI and placebo groups. Among these groups, body weight increased with time, but it was not significantly different ( $p=0.7985$; Supplementary Figure S1). Long-term follow-up for mouse death rate was not significant between the treatment and placebo groups (Fisher exact $p=0.8372$ ).

\subsection{Change in Consumption Ratio and Amount of Areca-Nut Water after Antidepressant Treatment}

We then evaluated the changes in the preference ratio of AN water after long -term antidepressant treatment. Preference ratio was defined as the consumption amount of AN water divided by the amount of normal drinking water in a free-selection condition. Formula = consumption amount of AN water (average ml per week)/consumption amount of normal drinking water (average mL per week). Results are presented in Table 1 (top), showing a decreased consumption ratio $(12.44 \%)$ in the Placebo A group $(p=0.16)$. After the 36-week follow-up, the consumption ratio was decreased by $17.49 \%$ in the MAOI treatment $(p=0.04)$ and $42.81 \%$ in the SSRI treatment group $(p=0.02)$ compared to before treatment. The consumption ratio decreased by $17.43 \%$ in the Placebo A group $(p=0.12)$. The TCA and Placebo B groups were not significantly decreased after antidepressant treatment (Table 1, bottom). Because the TCA group was not significantly decreased in preference ratio compared to the placebo group, the follow-up period was halted at four weeks after treatment. More detailed changes are presented in Supplementary Figure S2.

Table 1. Changes in weekly preference ratio $( \pm S D)$ with consumption of area nut water after antidepressants treatment in mouse mode (follow-up at 4 and 36 weeks).

\begin{tabular}{|c|c|c|c|c|c|c|c|c|}
\hline Groups & $\mathbf{N}$ & Baseline & $\begin{array}{c}\text { 4-Week } \\
\text { Follow-Up }\end{array}$ & $\begin{array}{l}\text { 36-Week } \\
\text { Follow-Up }\end{array}$ & $\begin{array}{c}\text { Changes in } \\
\text { 4-Week } \\
\text { Follow-Up (\%) }\end{array}$ & $p$ Value & $\begin{array}{c}\text { Changes in } \\
\text { 36-Week } \\
\text { Follow-Up (\%) }\end{array}$ & $p$ Value \\
\hline Placebo A & 15 & $1.63(0.38)$ & $1.43(0.47)$ & $1.34(0.49)$ & 12.2 & 0.16 & 17.8 & 0.12 \\
\hline MOAI & 15 & $1.43(0.39)$ & $0.70(0.55)$ & $1.18(0.15)$ & 51.0 & $<0.01$ & 17.5 & 0.04 \\
\hline SSRI & 10 & $1.58(0.94)$ & $1.07(0.34)$ & $0.90(0.33)$ & 32.3 & 0.03 & 42.8 & 0.02 \\
\hline Placebo B & 10 & $1.34(0.36)$ & $1.22(0.32)$ & - & 8.96 & 0.26 & - & - \\
\hline TCA & 5 & $1.19(0.44)$ & $1.08(0.30)$ & - & 9.24 & 0.24 & - & - \\
\hline
\end{tabular}

Preference ratio defined that consumption amount of areca nut water was divided by the amount of normal drinking water in free-selection condition. Formula = consumption amount of areca nut water $(\mathrm{mL} /$ weekly)/consumption amount of normal drinking water ( $\mathrm{mL} /$ weekly). TCA group was not significantly decreased in preference ratio compared to placebo group. Follow-up period was halted at 4 weeks after treatment. SD: standard deviation.

We performed MANOVA to evaluate changes in consumption amount (average $\mathrm{mL} /$ week) of AN water after antidepressant treatment in the four- and 36-week follow-ups. Average consumption amounts per week at baseline in the placebo, MAOI, and SSRI group were $21.7 \pm 4.92,19.6 \pm 4.19$, and $18 \pm 11.6$, respectively. There was no significant difference among the groups at the baseline $(p=0.385)$. The antidepressant treatment $\times$ time interaction represents the main between-group comparison in the consumptionamount changes across time (Table 2). The results show that there was a statistically significant difference between the MAOI treatment and placebo groups at the two- and four-week follow-ups ( $p=0.001$ and $p=0.0175)$. After the 36-week follow-up, there was no significant difference between the MAOI treatment and placebo group. However, there was statistically significant difference between the SSRI treatment and placebo groups at the four- and 36-week follow-ups ( $p=0.0091$ and $p=0.0454$ ), but there was no significant 
difference between the MAOI treatment and placebo group at the two-week follow-up. Repeated-measures ANOVA for antidepressant treatment showed significant differences regarding time, and the interaction between follow-up time and MAOI treatment group ( $p=0.0002$ at two weeks, $p<0.0001$ at four weeks; $p=0.0001$ at 36 weeks). The interaction between the follow-up time and SSRI treatment was significantly decreased at the fourweek follow-up $(p=0.003)$. A GEE model was established to examine the interaction between antidepressant treatment and follow-up time. Results of GEE analysis were similar to those in the interaction between time and drug effects with MANOVA (Supplementary Table S1).

Table 2. Changes in consumption amount (averaged $\mathrm{mL} /$ per week) of area nut water after antidepressants treatment in mouse mode (follow-up 4 and 36 weeks).

\begin{tabular}{|c|c|c|c|c|c|c|c|c|c|c|c|}
\hline \multirow[b]{2}{*}{ Scale } & \multirow[b]{2}{*}{$\begin{array}{l}\text { Placebo, Mean } \\
\quad \pm \text { SD }(n)\end{array}$} & \multirow[b]{2}{*}{$\underset{(n)}{\mathrm{MOAI} \pm \mathrm{SD}}$} & \multirow[b]{2}{*}{$\begin{array}{l}\text { SSRI, Mean } \pm \\
\text { SD }(n)\end{array}$} & \multicolumn{4}{|c|}{ MAOI } & \multicolumn{4}{|c|}{ SSRI } \\
\hline & & & & $\mathbf{F}$ & $p$ & $F^{a}$ & $p^{\mathrm{a}}$ & $\mathbf{F}$ & $p$ & $\mathbf{F}^{\mathbf{a}}$ & $p^{\mathrm{a}}$ \\
\hline Baseline & $21.7 \pm 4.92(15)$ & $19.6 \pm 4.19(15)$ & $18 \pm 11.6(10)$ & 0.34 & 0.5656 & 0.39 & 0.537 & 0.46 & 0.5023 & 1.02 & 0.3265 \\
\hline Weeks 1-2 & $26.2 \pm 4.19$ & $6.7 \pm 8.96(15)$ & $26.05 \pm 11.4(10)$ & 16.94 & 0.0003 & 14.3 & 0.001 & 0.1 & 0.9763 & 0.79 & 0.3879 \\
\hline Weeks 3-4 & $21.0 \pm 6.30(15)$ & $7.4 \pm 5.08(15)$ & $8.2 \pm 4.3(10)$ & 11.14 & 0.0024 & 6.6 & 0.0175 & 8.06 & 0.0093 & 8.66 & 0.0091 \\
\hline Weeks 36 & $25.1 \pm 5.84(15)$ & $19.2 \pm 4.15(15)$ & $15.7 \pm 5.46(10)$ & 1.96 & 0.1749 & 0.5 & 0.4867 & 4.81 & 0.0418 & 4.66 & 0.0454 \\
\hline $\begin{array}{c}\text { Drug } \\
\text { Week } 1-2 \times \text { drug }\end{array}$ & & & & 16.83 & 0.0003 & 18.28 & 0.0002 & 0.69 & 0.4137 & 0.3 & 0.8714 \\
\hline Week 3-4 × drug & & & & 12.53 & $<0.0001$ & 13.33 & $<0.0001$ & 3.46 & 0.0398 & 3.62 & 0.0351 \\
\hline Week $36 \times$ drug & & & & 12.2 & $<0.0001$ & 8.16 & 0.0001 & 1.53 & 0.2175 & 0.98 & 0.4118 \\
\hline
\end{tabular}

MANOVA was performed to examine interaction between antidepressant intervention $\times$ time effects (before and after treatment- 36 week follow up). a Mean changes were analyzed between two groups (MAOI vs placebo; SSRI vs placebo) by MANOVA with adjustment for mice weight.

\subsection{Difference in Fibrosis Levels and Risk between Treatment and Placebo Groups}

H\&E-stained tongue specimens from the antidepressant-treatment and placebo groups showed normal tongue features and mouse OSF. Figure 2A shows a photomicrograph showing OSF (blue) in mouse tongue tissue. Fibrosis indices are shown in the bar graphs between the study groups. The MAOI and SSRI groups had significantly lower fibrosis index values (Figure 2B; $p=0.01$ and $p=0.0081$, respectively). Moreover, the fibrogenesis process was protected in the SSRI treatment group compared to in the placebo group ( $\mathrm{HR}=0.08,95 \%$ CI: 0.01-0.76; and HR $=0.19,95 \%$ CI: 0.05-0.7; respectively, $p<0.01$; Table 3). Figure 3 shows the Kaplan-Meier curve for fibrosis risk rate according to treatment group. After the 60-week follow-up, the fibrosis risk rate for the MAOI and SSRI groups was significantly lower than that for the placebo group ( $p=0.0407$ and 0.0016 , respectively).

Table 3. Hazard ratio for oral submucous fibrosis occurrence in different treatment groups compared with placebo group.

\begin{tabular}{ccccc}
\hline & N (Expired) & \multicolumn{2}{c}{ Fibrosis Index $(\geqq 5)$} & No \\
Number of mice & $45(5)$ & & & HR (95\%CI) \\
Groups & & & & \\
Placebo & $23(2)$ & $9(39.1)$ & $14(60.9)$ & 1 \\
MAOI & $13(2)$ & $9(69.2)$ & $4(30.8)$ & $0.29(0.06-1.21)$ \\
SSRI & $9(1)$ & $8(88.9)$ & $1(11.1)$ & $0.08(0.01-0.76)$ \\
MAOI + SSRI & $22(3)$ & $17(77.3)$ & $5(22.7)$ & $0.19(0.05-0.70)$ \\
\hline
\end{tabular}


A

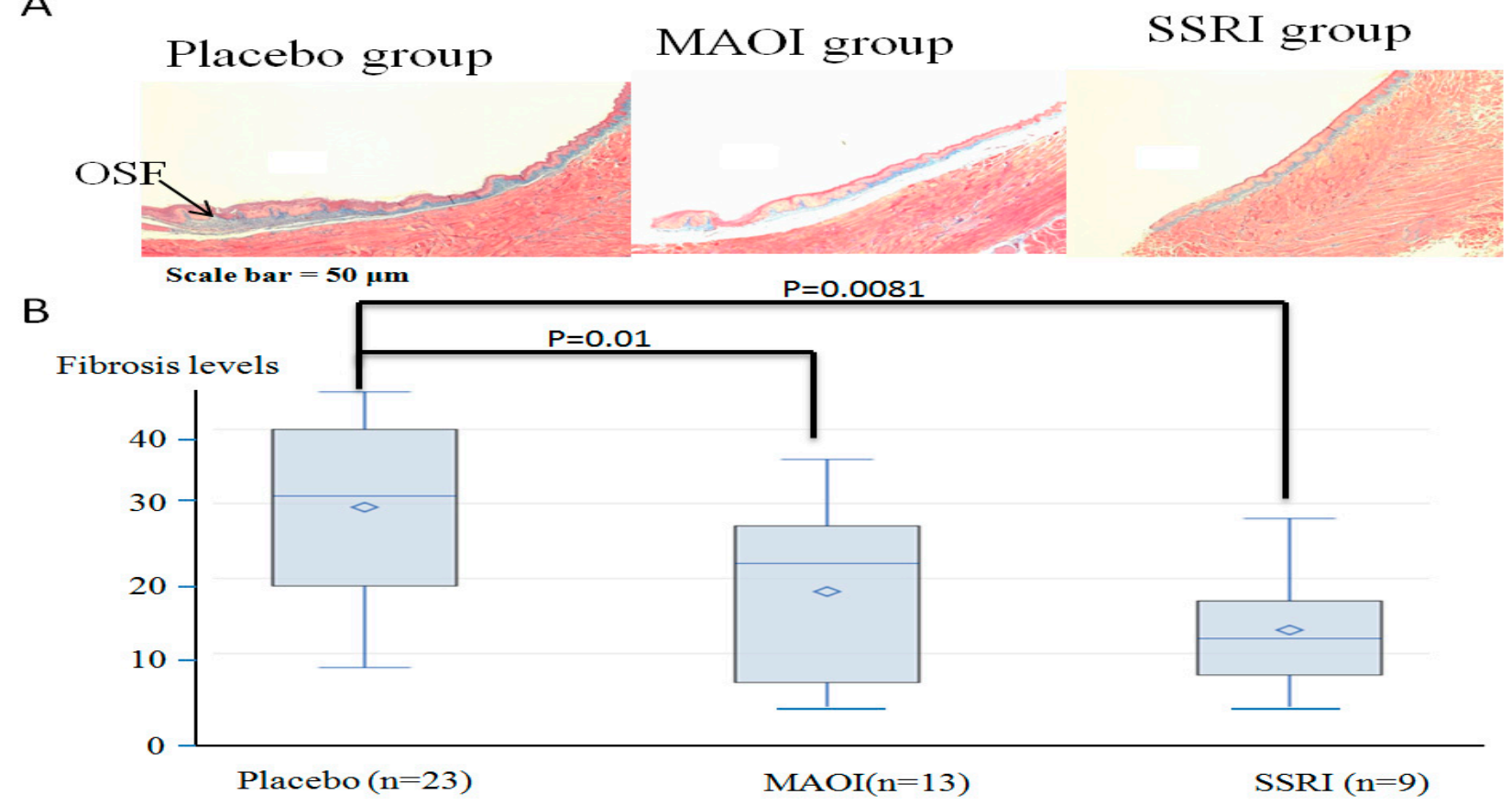

Figure 2. (A) H\&E (upper) trichrome of oral submucous fibrosis in mouse tongue tissue. Photomicrograph showing oral submucous fibrosis (blue) in mouse tongue tissue. Scale bar $=50 \mu \mathrm{m}$. Quantification of fibrosis levels obtained from ImageJ software. (B) Fibrosis levels treated by MAOI and SSRI compared to placebo group.

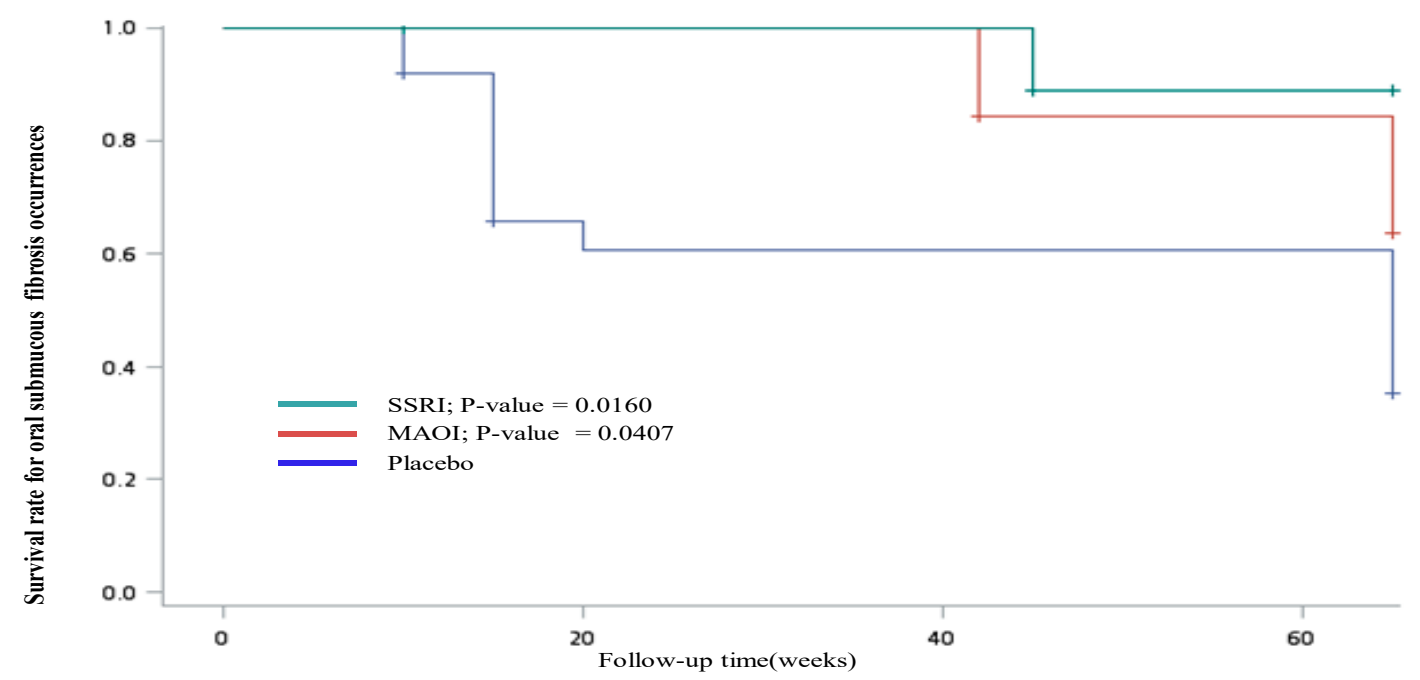

Figure 3. Effects of areca-nut use on oral submucous fibrosis risk after antidepressant treatment analyzed with Kaplan-Meier method in animal model.

\section{Discussion}

MAOI and SSRI treatment decreased AN consumption and OSF risks. The antidepressant properties of $\mathrm{BQ}$ and arecoline were reported to directly inhibit MAO-A enzymatic activity in cell, rat, and human models [37-40]. MAO-A metabolizes various primary, secondary, and tertiary monoamines, and preferentially deaminates neurotransmitters relative to depression. MAOI is used in the treatment of clinical depression and may be used for BQ cessation. Spring et al. found that fluoxetine, an SSRI, initially increased smoking cessation among smokers with a history of depressive disorders [41]. SSRIs were shown to inhibit serotonin reuptake by blocking serotonin transporters, thus probably 
decreasing the risk of smoking initiation and nicotine dependence, and increasing the likelihood of success of smoking cessation [42]. Arecoline is an important AN ingredient and has a comparable chemical structure to that of nicotine. SSRI treatment reduced AN consumption in our animal model. The potential mechanism is related to the effect of dopamine crosstalk with the release of serotonin in the brain, and there is strong evidence that serotonergic tone plays a role in the effects of addiction. Some studies reported that therapy with nortriptyline, a TCA, appears to be effective in the treatment of nicotine addiction $[43,44]$. However, in this study, TCA treatment did not significantly reduce the consumption amount of AN compared to in the placebo group.

OSF is a chronic disorder characterized by fibrosis of the mucosa lining the upper digestive tract involving the oral cavity, oro- and hypopharynx, and upper third of the esophagus, predominantly seen in people of South and Southeast Asia [45]. The main etiologic agent causing OSF was confirmed to be compounds and fibers in AN. The IARC classified 'BQ without tobacco', 'BQ with tobacco', and AN as carcinogenic to humans (Group 1) [3]. Cigarette smoking significantly contributes to the risk of leukoplakia, but does not contribute to OSF. BQ-chewing users with OSF experienced a higher risk at each exposure level of chewing duration, quantity, and cumulative measure than that of those who had leukoplakia $[4,5,25]$. The malignant transformation rate of OSF was reported to be over $2 \%$ per year [46]. Several studies were recently conducted to determine the possible mechanisms involved in malignant transformation. Until now, no single molecular pathway has been identified that is either necessary or sufficient for the development of fibrosis. This bars any molecularly targeted therapies. Because AN plays a major etiologic role in OSF, the cessation of AN use remains pivotal in the management of this disorder. Our study demonstrated that MAOI and SSRI treatment could reduce oral fibrosis levels via decreasing the consumption amount of AN in the mouse model.

MAOI treatment significantly decreased the consumption amount of AN at the twoand four-week follow-up, but no significant decrease was observed at 36 weeks. The interaction between follow-up time and MAOI treatment was significantly decreased at the two-, four-, and 36-week follow-up. However, SSRI treatment significantly decreased the amount of AN consumed at the four- and 36-week follow-ups. The interaction between the follow-up time and SSRI treatment was only significantly decreased at the four-week follow-up. The study of Hung et al. demonstrated that a reduction in daily BQ consumption after antidepressant therapy, including MAO-A inhibitors and SSRIs, was observed among patients with depression $[47,48]$. Our study and previous clinical trials provide preliminary evidence for appropriate treatments for the cessation of AN addiction.

SSRI treatment also has more protective effects on reducing OSF risk compared to those from the MAOI treatment. Serotonin is a stimulator of tissue fibrosis [49] and binds the $5-\mathrm{HT}_{2 \mathrm{~B}}$ receptor on fibroblasts, leading to fibroblast activation. Serotonin and the $5-\mathrm{HT}_{2 \mathrm{~B}}$ receptor are associated with fibrosis [50]. The agonism of 5- $\mathrm{HT}_{2 \mathrm{~B}}$ was implicated in fibrosis caused by fenfluramine, used in the treatment of obesity [51] and psychiatric disorders [52], both of which trigger 5- $\mathrm{HT}_{2 \mathrm{~B}}$ signaling. Dopamine agonists with structural similarity to 5-HT, such as pergolide and cabergoline, which are used in the treatment of Parkinson's disease, are also associated with the development of fibrosis in heart valves involving 5- $\mathrm{HT}_{2 \mathrm{~B}}$ agonism [53]. In addition to SSRIs, Alsamman et al. demonstrated that tricyclic antidepressants reduce hepatic fibrosis by inhibiting acid ceramidase [54].

To our knowledge, this is the first animal study to report that SSRIs can reduce the risk of oral fibrosis. The association and potential mechanisms between SSRIs and inhibition of oral fibrosis need to be investigated. SSRI treatment has long-term effects on decreasing the consumption amount of AN compared to those of MAOI treatment because SSRIs have a synergic effect on reducing the consumption amount of AN and inhibiting fibrosis activation. SSRIs may need to be boosted again, or the dose may need to be increased to efficiently reduce AN consumption.

This study has limitations. First, no serum and urine markers for metabolites of AN were utilized as evidence of cessation. The effect of cessation was neither validated nor 
measured in the mouse model. We only presented the decreased consumption preference ratio and amounts of AN. We cannot present the complete cessation rate in this study. Second, the consumption amounts of AN were not significant in the TCA treatment, which may have been due to the small sample size in the TCA group. Third, clinical indices for the assessment of liver fibrosis are well-established. However, clinical histopathological criteria for other fibrosis diseases have rarely been developed. In this study, a mouse model with long-term areca-nut treatment for the very early stage of oral fibrosis was employed. Accordingly, we used software to measure collagen deposition and assess the effects of antidepressants on oral fibrosis. We demonstrated that antidepressants could reduce oral fibrosis levels and risk in experimental subgroups in cross-sectional data. Without investigating proper control groups of experimental animals and limited sample sizes, we cannot examine the changes of fibrosis levels in the different doses of antidepressants and time duration.

\section{Conclusions}

After long-term follow-up, MAOI and SSRI treatments could reduce AN consumption and decrease very early stage oral fibrosis in a mouse model. These results may allow clinicians to provide appropriate treatment for the cessation of AN consumption and provide alternative ways to reduce OSF and oral-cancer risk.

Supplementary Materials: The following are available online at https:/ /www.mdpi.com/article/10 .3390/jpm11070591/s1, Figure S1: Comparison of body weight changes with long-term areca nut treatment among MAOI, SSRI and Placebo groups, Figure S2: Comparison in consumption amount of areca nut water after antidepressants treatment in mouse mode (follow-up 4 weeks and 36 weeks). TCA group was not significantly decreased in consumption amount of areca nut compared to placebo group. The follow-up period was halted at fourth weeks after treatment, Figure S3: H\&E trichrome of oral submucous fibrosis in the mouse tongue tissue. Photomicrograph showing oral submucous fibrosis (Blue color) in mouse tongue tissue. Scale bar $=50 \mu \mathrm{m}$. A: placebo group $(n=23)$, B. MAOI group ( $n=13)$, C. SSRI group $(n=9)$ Figure S4: H\&E trichrome of oral submucous fibrosis in the selective and paired mouse tongue tissue, Table S1: Changes in consumption amount (averaged $\mathrm{mL} /$ weekly) of area nut water after antidepressants treatment analyzed by GEE model.

Author Contributions: C.-M.C. and Y.-C.K., study concept and design; C.-M.C. and T.-M.K., acquisition of animal data; C.-M.C., Y.-C.K. and C.-H.L., data analysis and interpretation of findings; K.-T.Y., interpretation of immunohistochemical data; C.-M.C. and Y.-C.K., manuscript drafting. All authors have read and agreed to the published version of the manuscript.

Funding: This work was supported by the Ministry of Science and Technology MOST106-2314-B039-016-MY3 (Y.C. Ko).

Institutional Review Board Statement: Animal procedures conformed to the guidelines published by the National Institute of Health (NIH publication no. 85-23), and were approved by the Institutional Animal Care and Use Committee (IACUC) of the China Medical University.

Informed Consent Statement: Not applicable.

Data Availability Statement: The data presented in this study are available on request from the corresponding author.

Conflicts of Interest: The authors declare no conflict of interest.

\section{References}

1. Boucher, B.J.; Mannan, N. Metabolic effects of the consumption of Areca catechu. Addict. Biol. 2002, 7, 103-110. [CrossRef]

2. Gupta, P.C.; Ray, C.S. Epidemiology of betel quid usage. Ann. Acad. Med. 2004, 33, 31-36.

3. IARC Working Group on the Evaluation of Carcinogenic Risks to Humans. Betel-quid and areca-nut chewing and some areca-nut derived nitrosamines. IARC Monogr. Eval. Carcinog. Risks Hum. 2004, 85, 1-334.

4. Shiu, M.N.; Chen, T.H.H.; Chang, S.H.; Hahn, L.J. Risk factors for leukoplakia and malignant transformation to oral carcinoma: A leukoplakia cohort in Taiwan. Br. J. Cancer 2000, 82, 1871-1874. [CrossRef] [PubMed]

5. Yang, Y.-H.; Lee, H.-Y.; Tung, S.; Shieh, T.-Y. Epidemiological survey of oral submucous fibrosis and leukoplakia in aborigines of Taiwan. J. Oral Pathol. Med. 2001, 30, 213-219. [CrossRef] [PubMed] 
6. $\quad$ Lee, C.-H.; Ko, A.M.-S.; Yen, C.-F.; Chu, K.-S.; Gao, Y.-J.; Warnakulasuriya, S.; Sunarjo; Ibrahim, S.O.; Zain, R.B.; Patrick, W.K.; et al. Betel-quid dependence and oral potentially malignant disorders in six Asian countries. Br. J. Psychiatry 2012, 201, 383-391. [CrossRef]

7. Lee, C.-H.; Lee, K.-W.; Fang, F.-M.; Wu, D.-C.; Tsai, S.-M.; Chen, P.-H.; Shieh, T.-Y.; Chen, C.-H.; Wu, I.-C.; Huang, H.-L.; et al. The neoplastic impact of tobacco-free betel-quid on the histological type and the anatomical site of aerodigestive tract cancers. Int. J. Cancer 2012, 131, E733-E743. [CrossRef] [PubMed]

8. Ko, Y.-C.; Huang, Y.-L.; Lee, C.-H.; Chen, M.-J.; Lin, L.-M.; Tsai, C.-C. Betel quid chewing, cigarette smoking and alcohol consumption related to oral cancer in Taiwan. J. Oral Pathol. Med. 1995, 24, 450-453. [CrossRef]

9. Lee, C.-H.; Lee, J.-M.; Wu, D.-C.; Hsu, H.-K.; Kao, E.-L.; Huang, H.-L.; Wang, T.-N.; Huang, M.-C.; Wu, M.-T. Independent and combined effects of alcohol intake, tobacco smoking and betel quid chewing on the risk of esophageal cancer in Taiwan. Int. J. Cancer 2004, 113, 475-482. [CrossRef]

10. Lee, K.-W.; Kuo, W.-R.; Tsai, S.-M.; Wu, D.-C.; Wang, W.-M.; Fang, F.-M.; Chiang, F.-Y.; Ho, K.-Y.; Wang, L.-F.; Tai, C.-F.; et al. Different impact from betel quid, alcohol and cigarette: Risk factors for pharyngeal and laryngeal cancer. Int. J. Cancer 2005, 117, 831-836. [CrossRef]

11. Lee, C.-H.; Lee, K.-W.; Fang, F.-M.; Wu, D.-C.; Shieh, T.-Y.; Huang, H.-L.; Chen, C.-H.; Chen, P.-H.; Chen, M.-K.; Kuo, S.-J.; et al. The use of tobacco-free betel-quid in conjunction with alcohol/tobacco impacts early-onset age and carcinoma distribution for upper aerodigestive tract cancer. J. Oral Pathol. Med. 2011, 40, 684-692. [CrossRef]

12. Chen, P.-H.; Mahmood, Q.; Mariottini, G.L.; Chiang, T.-A.; Lee, K.-W. Adverse Health Effects of Betel Quid and the Risk of Oral and Pharyngeal Cancers. BioMed Res. Int. 2017, 2017, 3904098. [CrossRef]

13. Hsu, H.-F.; Tsou, T.-C.; Chao, H.-R.; Shy, C.-G.; Kuo, Y.-T.; Tsai, F.-Y.; Yeh, S.-C.; Ko, Y.-C. Effects of arecoline on adipogenesis, lipolysis, and glucose uptake of adipocytes-A possible role of betel-quid chewing in metabolic syndrome. Toxicol. Appl. Pharmacol. 2010, 245, 370-377. [CrossRef] [PubMed]

14. Lin, S.-H.; Liao, Y.-S.; Huang, S.-H.; Liao, W.-H. Relationship between betel quid chewing and risks of cardiovascular disease in older adults: A cross-sectional study in Taiwan. Drug Alcohol Depend. 2014, 141, 132-137. [CrossRef] [PubMed]

15. Yang, M.-S.; Lee, C.-H.; Chang, S.-J.; Chung, T.-C.; Tsai, E.-M.; Ko, A.M.-J.; Ko, Y.-C. The effect of maternal betel quid exposure during pregnancy on adverse birth outcomes among aborigines in Taiwan. Drug Alcohol Depend. 2008, 95, 134-139. [CrossRef]

16. Winstock, A.R.; Trivedy, C.R.; Warnakulasuriya, K.A.A.S.; Peters, T.J. A dependency syndrome related to areca nut use: Some medical and psychological aspects among areca nut users in the Gujarat community in the UK. Addict. Biol. 2000, 5, 173-179. [CrossRef] [PubMed]

17. Lord, G.A.; Lim, C.K.; Warnakulasuriya, S.; Peters, T.J. Chemical and analytical aspects of areca nut. Addict. Biol. 2002, 7, 99-102. [CrossRef]

18. Chu, N.S. Effects of Betel chewing on the central and autonomic nervous systems. J. Biomed. Sci. 2001, 8, 229-236. [CrossRef]

19. Winstock, A. Areca nut-abuse liability, dependence and public health. Addict. Biol. 2002, 7, 133-138. [CrossRef]

20. Bhat, S.J.S.; Blank, M.D.; Balster, R.L.; Nichter, M.; Nichter, M. Areca nut dependence among chewers in a South Indian community who do not also use tobacco. Addiction 2010, 105, 1303-1310. [CrossRef]

21. Lee, C.-H.; Chiang, S.-L.; Ko, A.M.-S.; Hua, C.-H.; Tsai, M.-H.; Warnakulasuriya, S.; Ibrahim, S.O.; Sunarjo; Zain, R.B.; Ling, T.-Y.; et al. Betel-quid dependence domains and syndrome associated with betel-quid ingredients among chewers: An Asian multi-country evidence. Addiction 2014, 109, 1194-1204. [CrossRef]

22. Lee, C.-H.; Ko, A.M.-S.; Yang, F.M.; Hung, C.-C.; Warnakulasuriya, S.; Ibrahim, S.O.; Zain, R.B.; Ko, Y.-C. Association of DSM-5 Betel-Quid Use Disorder with Oral Potentially Malignant Disorder in 6 Betel-Quid Endemic Asian Populations. JAMA Psychiatry 2018, 75, 261-269. [CrossRef]

23. Ko, A.M.-S.; Lee, C.-H.; Ko, Y.-C. Betel quid-associated cancer: Prevention strategies and targeted treatment. Cancer Lett. 2020, 477, 60-69. [CrossRef]

24. Tilakaratne, W.M.; Ekanayaka, R.P.; Warnakulasuriya, S. Oral submucous fibrosis: A historical perspective and a review on etiology and pathogenesis. Oral Surg. Oral Med. Oral Pathol. Oral Radiol. 2016, 122, 178-191. [CrossRef] [PubMed]

25. Lee, C.-H.; Ko, Y.-C.; Huang, H.-L.; Chao, Y.-Y.; Tsai, C.-C.; Shieh, T.-Y.; Lin, L.-M. The precancer risk of betel quid chewing, tobacco use and alcohol consumption in oral leukoplakia and oral submucous fibrosis in southern Taiwan. Br. J. Cancer 2003, 88, 366-372. [CrossRef] [PubMed]

26. Wang, Y.Y.; Tail, Y.H.; Wang, W.C.; Chen, C.Y.; Kao, Y.H.; Chen, Y.K.; Chen, C.H. Malignant transformation in 5071 southern Taiwanese patients with potentially malignant oral mucosal disorders. BMC Oral Health 2014, 14, 99. [CrossRef] [PubMed]

27. Lin, C.-F.; Wang, J.-D.; Chen, P.-H.; Chang, S.-J.; Yang, Y.-H.; Ko, Y.-C. Predictors of betel quid chewing behavior and cessation patterns in Taiwan aborigines. BMC Public Health 2006, 6, 271. [CrossRef]

28. Ghani, W.M.N.; Razak, I.; Yang, Y.-H.; Talib, N.; Ikeda, N.; Axell, T.; Gupta, P.C.; Handa, Y.; Abdullah, N.; Zain, R.B. Factors affecting commencement and cessation of betel quid chewing behaviour in Malaysian adults. BMC Public Health 2011, 11, 82. [CrossRef] [PubMed]

29. Chung, C.-M.; Kuo, T.-M.; Chiang, S.-L.; Wang, Z.-H.; Lane, H.-Y.; Liu, C.-S.; Ko, Y.-C.; Hung, C.-C. Antidepressants in association with reducing risk of oral cancer occurrence: A nationwide population-based cohort and nested case-control studies. Oncotarget 2016, 7, 11687-11695. [CrossRef] 
30. Osborne, P.G.; Ko, Y.-C.; Wu, M.-T.; Lee, C.-H. Intoxication and substance use disorder to Areca catechu nut containing betel quid: A review of epidemiological evidence, pharmacological basis and social factors influencing quitting strategies. Drug Alcohol Depend. 2017, 179, 187-197. [CrossRef]

31. Ko, A.M.; Lee, C.H.; Ko, A.M.; Ko, Y.C. Betel quid dependence mechanism and potential cessation therapy. Prog. Neuro Psychopharmacol. Biol. Psychiatry 2020, 103, 109982. [CrossRef]

32. Qiu, F.; Zhong, X.; Mao, Q.; Huang, Z. The antidepressant-like effects of paeoniflorin in mouse models. Exp. Ther. Med. 2013, 5, 1113-1116. [CrossRef] [PubMed]

33. Reimets, R.; Raud, S.; Loomets, M.; Visnapuu, T.; Volke, V.; Reimets, A.; Plaas, M.; Vasar, E. Variability in the effect of antidepressants upon Wfs1-deficient mice is dependent on the drugs' mechanism of actions. Behav. Brain Res. 2016, $308,53-63$. [CrossRef]

34. Wróbel, A.; Serefko, A.; Wlaź, P.; Poleszak, E. The depressogenic-like effect of acute and chronic treatment with dexamethasone and its influence on the activity of antidepressant drugs in the forced swim test in adult mice. Prog. Neuro Psychopharmacol. Biol. Psychiatry 2014, 54, 243-248. [CrossRef] [PubMed]

35. Biradar, S.; Munde, A.; Biradar, B.; Shaik, S.; Mishra, S. Oral submucous fibrosis: A clinico-histopathological correlational study. J. Cancer Res. Ther. 2018, 14, 597. [CrossRef]

36. Pandya, S.; Chaudhary, A.K.; Singh, M.; Singh, M.; Mehrotra, R. Correlation of histopathological diagnosis with habits and clinical findings in oral submucous fibrosis. Head Neck Oncol. 2009, 1, 10. [CrossRef] [PubMed]

37. Chen, P.-H.; Tu, H.-P.; Wang, S.-J.; Ko, A.M.-S.; Lee, C.-P.; Chiang, T.-A.; Tsai, Y.-S.; Lee, C.-H.; Shieh, T.-Y.; Ko, C.-H.; et al. Monoamine oxidase A variants are associated with heavy betel quid use. Addict. Biol. 2011, 17, 786-797. [CrossRef]

38. Dar, A.; Khatoon, S. Behavioral and biochemical studies of dichloromethane fraction from the Areca catechu nut. Pharmacol. Biochem. Behav. 2000, 65, 1-6. [CrossRef]

39. Fowler, J.S.; Volkow, N.D.; Wang, G.-J.; Pappas, N.; Logan, J.; Shea, C.; Alexoff, D.; MacGregor, R.R.; Schlyer, D.J.; Zezulkova, I.; et al. Brain monoamine oxidase A inhibition in cigarette smokers. Proc. Natl. Acad. Sci. USA 1996, 93, 14065-14069. [CrossRef] [PubMed]

40. Osman, M.Y.; Osman, H.M. Inhibitory effect of acetylcholine on monoamine oxidase A and B activity in different parts of rat brain. Arzneim. Forsch. 2008, 58, 493-496. [CrossRef] [PubMed]

41. Spring, B.; Doran, N.; Pagoto, S.; McChargue, D.; Cook, J.W.; Bailey, K.; Crayton, J.; Hedeker, D. Fluoxetine, smoking, and history of major depression: A randomized controlled trial. J. Consult. Clin. Psychol. 2007, 75, 85-94. [CrossRef]

42. Seth, P.; Cheeta, S.; Tucci, S.; File, S.E. Nicotinic-serotonergic interactions in brain and behaviour. Pharmacol. Biochem. Behav. 2002, 71, 795-805. [CrossRef]

43. da Costa, C.L.; Younes, R.N.; Lourenco, M.T. Stopping smoking: A prospective, randomized, double-blind study comparing nortriptyline to placebo. Chest 2002, 122, 403-408. [CrossRef]

44. Hughes, J.R.; Stead, L.F.; Hartmann-Boyce, J.; Cahill, K.; Lancaster, T. Antidepressants for smoking cessation. Cochrane Database Syst. Rev. 2014, CD000031. [CrossRef]

45. Arakeri, G.; Rai, K.K.; Hunasgi, S.; Merkx, M.; Gao, S.; Brennan, P.A. Oral submucous fibrosis: An update on current theories of pathogenesis. J. Oral Pathol. Med. 2017, 46, 406-412. [CrossRef] [PubMed]

46. Napier, S.S.; Speight, P.M. Natural history of potentially malignant oral lesions and conditions: An overview of the literature. $J$. Oral Pathol. Med. 2008, 37, 1-10. [CrossRef] [PubMed]

47. Hung, C.C.; Lee, C.H.; Chung, C.M.; Nithiyanantham, S.; Lane, H.Y.; Ko, Y.C. Antidepressant-induced reduction in betel-quid use in patients with depression: A pioneer clinical study. Medicine 2020, 99, e18672. [CrossRef] [PubMed]

48. Hung, C.-C.; Lee, C.-H.; Ko, A.M.-S.; Lane, H.-Y.; Lee, C.-P.; Ko, Y.-C. Effect of antidepressants for cessation therapy in betel-quid use disorder: A randomised, double-blind, placebo-controlled trial. Epidemiol. Psychiatr. Sci. 2020, 29, e125. [CrossRef] [PubMed]

49. Oates, J.A.; Melmon, K.; Sjoerdsma, A.; Gillespie, L.; Mason, D.T. Release of a Kinin Peptide in the Carcinoid Syndrome. Lancet 1964, 1, 514-517. [CrossRef]

50. Dees, C.; Akhmetshina, A.; Zerr, P.; Reich, N.; Palumbo, K.; Horn, A.; Jungel, A.; Beyer, C.; Kronke, G.; Zwerina, J.; et al. Platelet-derived serotonin links vascular disease and tissue fibrosis. J. Exp. Med. 2011, 208, 961-972. [CrossRef] [PubMed]

51. Rothman, R.B.; Baumann, M.; Savage, J.E.; Rauser, L.; McBride, A.; Hufeisen, S.J.; Roth, B.L. Evidence for Possible Involvement of 5-HT 2B Receptors in the Cardiac Valvulopathy Associated with Fenfluramine and Other Serotonergic Medications. Circulation 2000, 102, 2836-2841. [CrossRef] [PubMed]

52. Fowles, R.E.; Cloward, T.V.; Yowell, R.L. Endocardial Fibrosis Associated with Fenfluramine-Phentermine. N. Engl. J. Med. 1998, 338, 1316-1317. [CrossRef] [PubMed]

53. Antonini, A.; Poewe, W. Fibrotic heart-valve reactions to dopamine-agonist treatment in Parkinson's disease. Lancet Neurol. 2007, 6, 826-829. [CrossRef]

54. Alsamman, S.; Christenson, S.A.; Yu, A.; Ayad, N.M.E.; Mooring, M.S.; Segal, J.M.; Hu, J.K.; Schaub, J.R.; Ho, S.S.; Rao, V.; et al. Targeting acid ceramidase inhibits YAP/TAZ signaling to reduce fibrosis in mice. Sci. Transl. Med. 2020, 12. [CrossRef] [PubMed] 